\title{
Efficacy of Sanitizing Treatments for Feline Calicivirus as a Norovirus Surrogate Attached to Food and Food Contact Surfaces
}

\author{
Sung-Young Lee and Kwang-Yup Kim ${ }^{\dagger}$ \\ Department of Food Science and Technology, Chungbuk National University, Chungbuk 361-763, Korea
}

\begin{abstract}
Norovirus (NV) is becoming a major cause of foodborne illness in many countries. At present, very little is known about the survival of $\mathrm{NV}$ in the environment or the disinfection procedures needed to remove $\mathrm{NV}$ from contaminated surfaces. Feline calicivirus (FCV, $1 \times 10^{6.75} \mathrm{TCID}_{50} / \mathrm{mL}$ ) was used as a surrogate model for NV to investigate the effectiveness of sanitizing treatments for the viruses attached to food and food contact surfaces. Ammonium chloride (2\%), organic acids (3000 ppm), and ethanol (70\%) were most effective, providing $4 \log _{10}$ (99.99\%) reductions in FCV titers on food or food contact surfaces. The disinfection efficacies of most agents on ceramic and glass surfaces were greater than stainless steel. The results from this study can be applied in the food industry to reduce $\mathrm{NV}$-associated foodbome illnesses.
\end{abstract}

Key words: norovirus, feline calicivirus, inactivation, $\mathrm{TCID}_{50}$, disinfectants

\section{INTRODUCTION}

Many countries now consider foodborne disease to be a major ongoing public health issue. In recent years, it has been recognized that viruses are an important cause of foodborne disease. Unlike bacteria, viruses do not multiply in or on foods, but foods may become contaminated with human viruses and transmit infection. Foodborne viruses include rotaviruses, adenoviruses, caliciviruses, norovirus (NV), and hepatitis A virus (HAV) (1-3). Although, there are numerous varieties of viruses transmitted via the fecal-oral route, most reports of foodborne transmission involve NV and HAV infections, suggesting that these two strains are associated with a greater risk of foodborne transmission. NV and HAV can be transmitted from person to person or indirectly, via food, water, or virus-containing feces or vomit. Characteristic symptoms of nausea, vomiting, and diarrhea typically appear after $24 \sim 48 \mathrm{hr}$ of incubation and last about $48 \sim$ $72 \mathrm{hr}$ (4). Most individuals recover completely without complications, but the very young, the elderly, and persons with weakened immune systems may require special care $(2,3,5,6)$. Transmission of these viruses by contaminated foods, especially oysters, vegetables, fruits, and water, has been documented $(2,7,8)$. In recent years, the incidence of NV food poisoning has increased rapidly in Korea. According to a report by the Division of Enteric Hepatitis Viruses, about $5.5 \%$ of acute diarrhea cases and $30 \%$ of viral diarrhea cases between 2003 and 2007 were due to NV. The Korean Food and Drug Administration reported that 97 of 510 foodborne outbreaks and 2345 of 9686 foodborne illnesses that occurred in 2007 were caused by NV (9). Recent advances in NV research have led to the development of methods that can be used to trace and detect viral strains. These methods can and have been used for the detection of common source outbreaks $(2,3,6,7,10,11)$; however, very little is known about the survival of NV in the environment or the disinfection procedures needed to remove $\mathrm{NV}$ from contaminated settings. Food contact surfaces have not been investigated for their role in the transmission of $\mathrm{NV}$, possibly because effective methods are not available for virus recovery from such surfaces. Consequently, it is necessary to assess disinfection protocols and the survival of $\mathrm{NV}$ in the environment. NV cannot be grown in cell culture; thus, cultivable feline calicivirus (FCV) was used as a surrogate model (4,5, 7,10-24). FCV and NV belong to the same family of Caliciviridae and their genetic and morphological properties are very similar. The objective of this study was to develop methods to recover FCV from food and food contact surfaces. We then evaluated several disinfectants for their ability to inactivate FCV.

\section{MATERIALS AND METHODS}

Food contact surfaces

The food contact surfaces were made of stainless steel, 
glass, and ceramic. Stainless steel (type 304 ss. no 4), glass, and ceramic surfaces of $26 \times 76 \mathrm{~mm}$ in area were fabricated. These surfaces were rinsed with distilled water, dried, and then autoclaved at $121^{\circ} \mathrm{C}$ for $15 \mathrm{~min}$.

\section{Food samples}

Beef and lettuce samples were obtained randomly from a market in the Cheongju area. Beef and lettuce samples were cut to $26 \times 76 \mathrm{~mm}$ in area and $1.0 \mathrm{~mm}$ thick. Each piece was put into a pre-sterilized Petri dish and artificially inoculated with FCV. The concentration of FCV was $1 \times 10^{6.75} \mathrm{TCID}_{50} / \mathrm{mL}$. The beef was stored at $-20^{\circ} \mathrm{C}$ and the lettuce was stored at $4^{\circ} \mathrm{C}$ until use.

\section{Treatments}

Physical treatments included ultraviolet irradiation (wavelength, $270.0 \mathrm{~nm}$ ), drying, freezing $\left(-20^{\circ} \mathrm{C}\right)$, and rinsing with tap water. Chemical treatments included sodium bicarbonate, hydrogen peroxide (Sigma-Aldrich, St. Louis, MO, USA), ethanol (Merck KGaA Co., Darmstadt, Germany), iodine (Shinyo Pure Chemical Co., Osaka, Japan), ammonium chloride (Tedia Co., Inc., Fairfield, OH, USA), isopropanol (Jin, Seoul, Korea), and trisodium phosphate (TSP; Showa Chemical Co., Tokyo, Japan). The organic acids used included acetic acid (Shinyo), benzoic acid (Sigma-Aldrich), citric acid (DC Chemical Co., Seoul, Korea), lactic acid (Tedia), and propionic acid (Sigma-Aldrich).

\section{Virus and cells}

FCV strain F9 (catalog no. VR-782) was purchased from the American Type Culture Collection (ATCC, Manassas, VA, USA) and propagated in Crandell-Reese feline kidney (CRFK) cells from the Korean Cell Line Bank (KCLB, Seoul, Korea). The cells were grown in Dulbecco's modified Eagle's medium (DMEM; Hyclone, Logan, UT, USA) supplemented with $10 \%$ fetal bovine serum (FBS; Hyclone), 1\% $10 \mathrm{mM}$ non-essential amino acids (NEAA; Gibco, Grand Island, NY, USA), and 1\% penicillin-streptomycin (Gibco). Cells were incubated at $37^{\circ} \mathrm{C}$ in a humidified chamber under $5 \% \mathrm{CO}_{2}$, and then divided into separate culture dishes when they were over $90 \%$ proliferated $(12,13,25)$. CRFK cell monolayers at $90 \%$ confluence were inoculated with FCV and incubated at $37^{\circ} \mathrm{C}$ in the maintenance medium (DMEM, $5 \%$ FBS, $1 \%$ penicillin-streptomycin, and $1 \%$ NEAA) for $3 \sim 4$ days. Virus stocks were stored in cryogenic vials (Nalgene, Rochester, NY, USA) in liquid nitrogen. Viruses were thawed in a $37^{\circ} \mathrm{C}$ water bath for $10 \mathrm{~min}$ prior to artificial inoculation.

\section{Tissue culture infectious dose 50 (TCID $_{50}$ )}

CRFK cells were maintained as stock cultures in DMEM and re-plated 2 days before infection in 96-well plates for $\operatorname{TCID}_{50}$ assays $(11,14)$. Treated samples and their paired controls were subjected to 10 -fold serial dilutions. The medium used for dilution and infection was Dulbecco's phosphate-buffered saline pH 7.4 (DPBS; Gibco). Samples of each dilution $(20 \mu \mathrm{L})$ were deposited in each of 10 wells in a 96-well plate. Following a 1-hr incubation at $37^{\circ} \mathrm{C}$ in a humidified chamber under $5 \%$ $\mathrm{CO}_{2}, 80 \mu \mathrm{L}$ of maintenance medium was added to each well. After 4 days of incubation, the cells were observed for cytopathic effects. The plate was washed and the remaining cells were stained with $0.5 \%$ methylene blue in $50 \%$ ethanol. The $50 \%$ tissue culture infectious dose $\left(\mathrm{TCID}_{50}\right)$ was calculated according to the method of Reed and Muench (26).

\section{Inactivation of viruses on food contact surfaces and} food surfaces

The food contact surfaces examined here were stainless steel, glass, and ceramic. The food surfaces used were lettuce and beef. Food contact surfaces and food surfaces were inoculated with FCV suspensions $(1 \mathrm{~mL})$. To allow for absorption of FCV, the sample surfaces were incubated at $37^{\circ} \mathrm{C}$ for $1 \mathrm{hr}$, and then physical, chemical, disinfectant, or organic acid treatments were administered. Sterile moistened cotton swabs were used to sample the surfaces by rubbing over an area of approximately $26 \times 76 \mathrm{~mm}$ (27). The contaminated area was exposed to $20 \mu \mathrm{L}$ of test solution or DPBS as a control. Treatment samples of each dilution $(20 \mu \mathrm{L})$ were deposited in each of 10 wells in a 96-well plate. Samples from the swabs were diluted in DPBS $\mathrm{pH}$ 7.4. Twenty $\mu \mathrm{L}$ of the samples which dilutes was exposed in 96-well plate. After $80 \mu \mathrm{L}$ of maintenance medium was added to a 96-well plate, the plate was agitated on a shaker platform at $150 \mathrm{rpm}$ for $30 \mathrm{~min}$. After 4 days of incubation, the cells were observed for cytopathic effects. Viral titers in the treated and control wells were compared to determine the extent of virus reduction.

\section{Inactivation by physical treatment}

The efficacy of four physical treatments was assessed. For the UV irradiation treatment, contaminated food contact surfaces and food surfaces were incubated under a germicidal lamp (length, $800 \mathrm{~mm}$; wavelength, 270.0 $\mathrm{nm}$; ozone free; DAE chung science, Daejeon, Korea) with a tubular glass envelope emitting short-wavelength UV radiation with a monochromatic peak at $270.0 \mathrm{~nm}$ for 10,20 , or $30 \mathrm{~min}$. In the drying treatment, food contact surfaces or food surfaces were inoculated with $\mathrm{FCV}$, allowed to dry for $10 \mathrm{~min}, 1,3,12,24$, or $48 \mathrm{hr}$, and then assessed. For the cold-storage treatment, surfaces were inoculated and then frozen at $-20^{\circ} \mathrm{C}$ for $0.5,1,12$, or $24 \mathrm{hr}$; the samples were then thawed and assessed. 
For the tap water treatment, food contact surfaces were inoculated with FCV suspensions and immersed in tap water. Following $0.5,1,12$, and $24 \mathrm{hr}$ of treatment, the test samples were serially diluted and assayed immediately to determine the $\mathrm{TCID}_{50}$.

\section{Inactivation by chemical treatment}

The following solutions were prepared in sterile distilled water: sodium bicarbonate $(0.1,0.5,1,5,10$, and $20 \%$ ); ammonium chloride $(0.1,2,6$, and $10 \%)$; hydrogen peroxide $(1,10,100$, and $1000 \mathrm{ppm})$; iodine $(5,15$, 25 , and $35 \mathrm{ppm})$; isopropanol $(40 \sim 60 \%)$; TSP (200, $1100,3000$, and $5900 \mathrm{ppm})$, and ethanol $(60,70$, and $80 \%$ ). The solubility of elemental iodine in water can be greatly increased by the addition of small amounts of chloroform or carbon tetrachloride, into which iodine easily dissolves. These solutions were evaluated for their inactivation of FCV dried onto food contact surfaces after an exposure of $1 \mathrm{~min}$ at room temperature; food contact surfaces exposed to $70 \%$ ethanol were also tested after a 30 -sec exposure. The test suspensions were diluted serially and assayed immediately to determine the $\mathrm{TCID}_{50}$.

\section{Inactivation by organic acid treatment}

Five different organic acids (acetic, benzoic, citric, lactic, and propionic acid) were tested on food surfaces (beef or lettuce) at concentrations of 100, 1000, 3000, or $6000 \mathrm{ppm}$. The test suspensions were diluted serially and assayed immediately to determine the $\mathrm{TCID}_{50}$.

\section{Calculation of disinfection efficacy}

After each treatment, performance was analyzed in terms of the reduction in FCV titer. The efficacy evaluation was performed as described (20,28-30).

\section{RESULTS AND DISCUSSION}

\section{Determination of TCID $_{50}$ for $\mathrm{FCV}$}

To measure the concentration of virus, the tissue cul- ture infectious dose $50\left(\mathrm{TCID}_{50}\right)$ assay was applied. In this study, the concentration of FCV was $1 \times 10^{6.75} \mathrm{TCID}_{50} /$ $\mathrm{mL}$ and serial dilutions of this suspension were used for each experiment.

\section{FCV inactivation on food contact surfaces}

Fig. 1 and Fig. 2 display the results for the various treatments used to disinfect FCV-contaminated surfaces. A treatment was considered effective if it caused $\mathrm{a} \geq 4$ $\log _{10}(99.99 \%)$ reduction in the number of infectious viral units compared to the untreated control. Generally, for antiviral efficacy testing, a 3 to $4 \log _{10}$ reduction in virus titer compared with control is used $(31,32)$. So, in this result, most treatments were able to cause $4 \log _{10}$ reductions in FCV titer.

FCV was used in the present study as a model for $\mathrm{NV}$ inactivation by UV light $(5,13,22,33)$. According to study, at least $99.99 \%$ inactivation would occur for FCV at the NSF-recommended dose of $40 \mathrm{~mJ} / \mathrm{cm}^{2}$ (33). Regarding the effect of UV irradiation on food contact surfaces, treatment for $30 \mathrm{~min}$ resulted in decreases of $99.42 \%$ and $99.41 \%$ on glass and ceramic surfaces, respectively (Fig. 1, A-3). A recent study reported that drying is relatively effective because virus on a metal surface would be directly exposed to dry air $(6,29)$. We found that a drying time of $48 \mathrm{hr}$ was most effective against FCV on food contact surfaces and that shorter exposure times were less effective. On stainless steel, freezing for $24 \mathrm{hr}$ was most effective, with a $96.9 \%$ reduction (Fig. 1, B-4). This results show that freezing has limited effects in removing FCV. In contrast, freezing did not significantly reduce the viability of any of the viruses except the infectivity of FCV. The exceptions were FCV on food, in which the $\mathrm{TCID}_{50}$ values were reduced by less than one $\log _{10}(5,34)$.

It has been demonstrated that transfer of the infectious viruses can readily occur by casual contact between

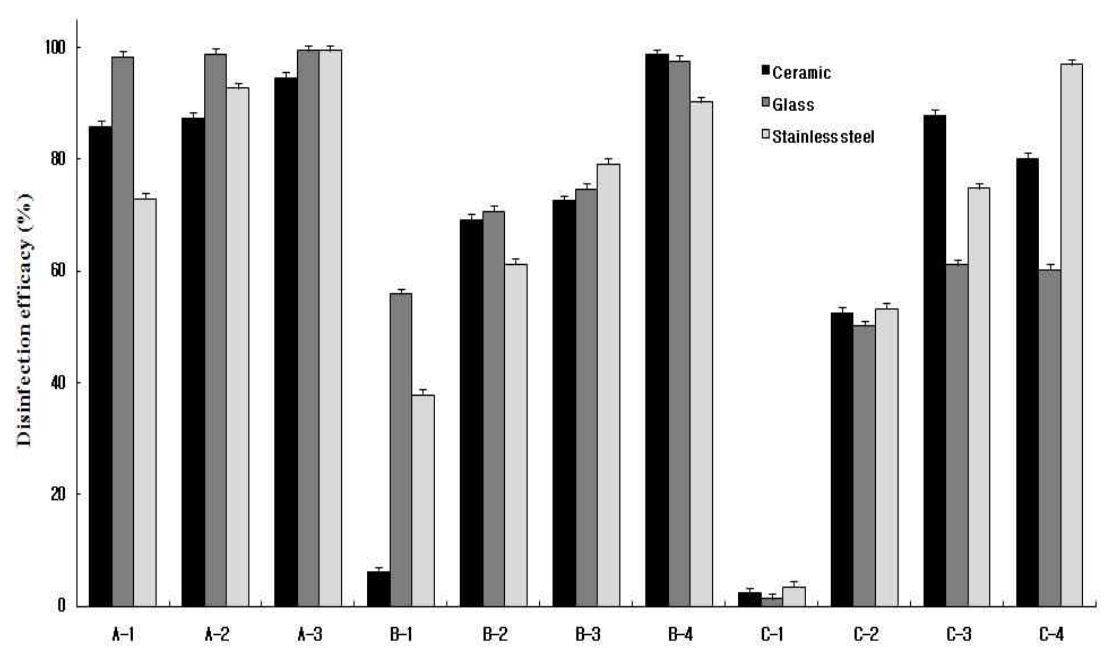

Fig 1. Comparison of the FCV inactivation efficacies of various physical treatments after inoculation of ceramic, glass, and stainless steel food contact surfaces. (A-1) UV $10 \mathrm{~min}$; (A-2) UV 20 min; (A-3) UV 30 min; (B-1) drying $10 \mathrm{~min}$; (B-2) drying $1 \mathrm{hr}$; (B-3) drying $12 \mathrm{hr}$; (B-4) drying $48 \mathrm{hr}$; (C-1) freezing 30 min; (C-2) freezing $1 \mathrm{hr}$; (C-3) freezing 12 $\mathrm{hr}$; (C-4) freezing $24 \mathrm{hr}$. 


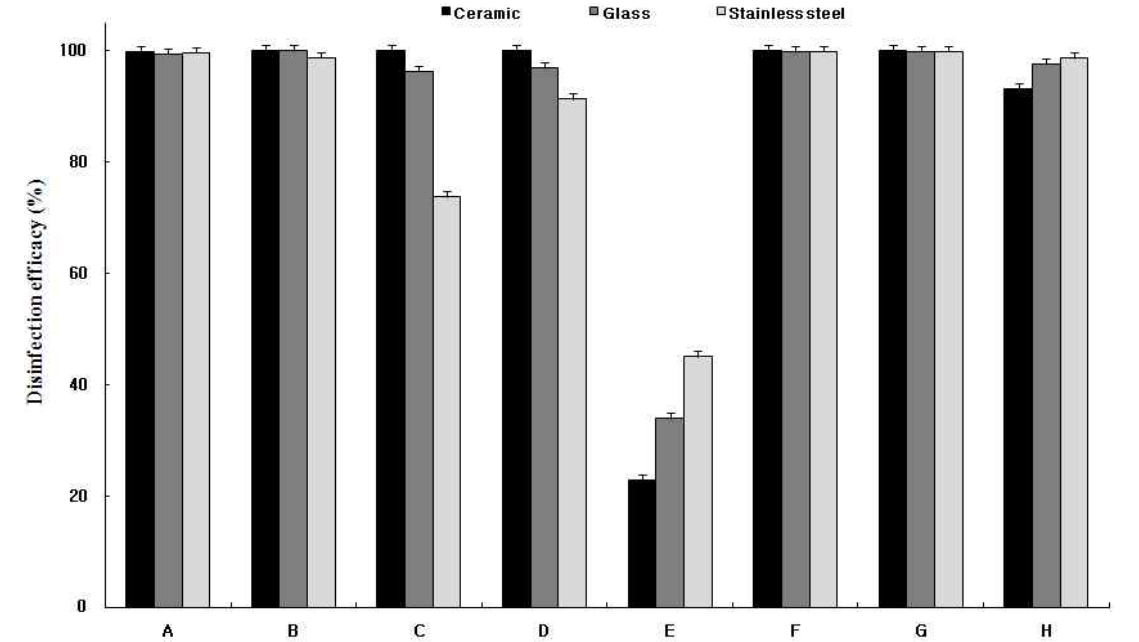

Fig 2. Comparison of the FCV inactivation efficacies of various chemical treatments (sodium bicarbonate, ammonium chloride, hydrogen peroxide, iodine, ethanol, isopropanol, and trisodium phosphate [TSP]) after inoculation of ceramic, glass, and stainless steel food contact surfaces. (A) sodium bicarbonate 5\%; (B) ammonium chloride $10 \%$; (C) hydrogen peroxide $100 \mathrm{ppm}$; (D) hydrogen peroxide 1000 ppm; (E) iodine 25 ppm; (F) ethanol 60\%; (G) isopropanol 60\%; (H) TSP 5900 ppm. foods and environmental surfaces and that NV is relatively resistant to inactivation by chemical and physical agents. Effective disinfection of surfaces may be useful in preventing or reducing the spread of NV. Because of the toxicity associated with chemical disinfectants, many commercially available disinfectants cannot be directly applied to the food contact surfaces. The disinfection efficacies of various concentrations of sodium bicarbonate, ammonium chloride, hydrogen peroxide, iodine, ethanol, isopropanol, and TSP against FCV after exposures of 1 min are shown in Fig. 2. In the past, sodium bicarbonate has been shown to be effective against bacteria, fungi, and FCV $(12,25,28,35)$. Sodium bicarbonate at concentrations of $0.1 \sim 20 \%$ reduced $86.2 \sim 99.73 \%$ of FCV (data not shown), with the most powerful effect at 5\% sodium bicarbonate, which killed 99.76, 99.38, and $99.57 \%$ of the virus on ceramic, glass, and stainless steel surfaces, respectively (Fig. 2, A). Quaternary ammonium-based compounds are reported to be the least effective against hydrophilic, non-enveloped viruses, such as FCV, canine parvovirus, and poliovirus $(17,36)$. In one study, quaternary ammonium-based compounds alone to be ineffective, but in combination with sodium bicarbonate they showed some anti-FCV activity. In these experiments, quaternary ammonium-based compounds were used in combination with sodium bicarbonate, and were able to cause a more than $3 \log _{10}$ reduction in FCV titer on stainless steel surfaces $(12,19)$. Ammonium chloride concentrations of $0.1 \sim 10 \%$ appeared to be more effective, with $99.9 \%$ virus inactivation occurring within 1 min (data not shown). The weakest inactivation was observed with 10\% ammonium chloride, which inactivated $98.71 \%$ of virus on stainless steel (Fig. 2, B). Hydrogen peroxide has been reported to be a potent disinfectant (36-38); however, higher concentrations of hydrogen peroxide sometimes lead to browning of produce
(36). On the ceramic surface, a hydrogen peroxide concentration of 1 ppm resulted in $99.99 \%$ inactivation, and the most potent effect was obtained with 100 ppm hydrogen peroxide, which killed 99.98, 99, and $99.25 \%$ of the virus on ceramic, glass, and stainless steel surfaces, respectively (Fig. 2, C-D). In previous studies, iodine was relatively ineffective, even at $300 \mathrm{ppm}(12,17)$; this is a concern, considering that a maximum of $75 \mathrm{ppm}$ is recommended by manufacturers for environmental surface disinfection, and the Korean Food and Drug Administration recommends $25 \mathrm{ppm}$ for sanitizing food contact surfaces (9). In this study, lower concentrations of iodine (5 $35 \mathrm{ppm})$ exhibited less than 50\% disinfection efficacy (data not shown). Within the iodine treatments, 25 ppm iodine provided the best results, killing 22.91, 33.94 , and $45.05 \%$ of the virus on ceramic, glass, and stainless steel surfaces, respectively (Fig. 2, E). In general, the most effective ethanol concentrations reported are greater than $50 \%$. However, in a previous study, ethanol concentrations greater than $70 \%$ were ineffective against FCV after a 1-min exposure (21). In the present study, ethanol was slightly less effective than isopropanol. This may be due to the reduced hydrophilic nature of FCV, which makes the virus more susceptible to isopropanol. In a previous study using cell suspensions, they found that isopropanol at $50 \sim 70 \%$ was more effective than $50 \sim 80 \%$ ethanol, killing more than $99.99 \%$ of FCV in less than $1 \mathrm{~min}(20)$. In this study, ethanol concentrations of 60,70 , and $80 \%$ appeared to be more effective than isopropanol, with $99.99 \%$ virus inactivation occurring within $1 \mathrm{~min}$ (data not shown). Among isopropanol treatment, a concentration of $60 \%$ had the most potent effect on FCV titers on food contact surfaces, killing 99.93, 99.83, and 99.88\% of the virus on ceramic, glass, and stainless steel surfaces, respectively (Fig. 2, G). TSP was used alone or in the presence of 
nisin, since these treatments have been previously shown to be effective against other pathogens in culture and in foods. For example, 10 min with $10 \%$ TSP at $48^{\circ} \mathrm{C}$, followed by incubation in the presence of $500 \mathrm{IUmL}^{-1}$ nisin, resulted in no viable cells being recovered after $24 \mathrm{hr}\left(2 \log _{10}\right.$ reduction cell kill) indicating that a multiple hurdle approach is the most effective method of reducing growth and survival of $A$. butzleri in culture (39). TSP at $200 \sim 5900 \mathrm{ppm}$ killed $1.62 \sim 98.59 \%$ of FCV (data not shown); the greatest inactivation was observed at 5900 ppm, which killed 93.08, 97.6, and $98.59 \%$ on ceramic, glass and stainless steel surfaces, respectively (Fig. 2, H).

\section{Disinfection of FCV on food surfaces}

The results of the physical treatments are shown in Fig. 3. To evaluate the effect of UV irradiation on contaminated beef or lettuce, inoculated food samples were irradiated for 10,20 , or $30 \mathrm{~min}$. The 30 -min UV treatment provided the best results for FCV on beef $(99 \%)$ and lettuce $(99.9 \%)$. Similarly, air-drying for $48 \mathrm{hr}$ inactivated 99.92 and $99.97 \%$ of the virus found on beef and lettuce, respectively (Fig. 3, B-4). We found that a drying time of $48 \mathrm{hr}$ was most effective against FCV on food contact surfaces and that shorter exposure times were less effective. Similar to the UV treatment results, inactivation by drying was slightly more effective for lettuce than beef.

The disinfection efficacy of various concentrations of acetic acid, benzoic acid, citric acid, lactic acid, and propionic acid against FCV after 1 min of contact is shown in Fig. 4. FCV-inoculated samples were treated with 100, 1000,3000 , or $5900 \mathrm{ppm}$ of each acid. Of the organic acids tested, propionic acid was most effective. Acetic acid and propionic acid at $3000 \mathrm{ppm}$ were most effective, whereas benzoic acid, citric acid and lactic acid were more effective at $5900 \mathrm{ppm}$. Acetic acid at concen- trations of 100 to $5900 \mathrm{ppm}$ concentration killed 87.98 to $99.84 \%$ of FCV. The most potent effect was observed with a concentration of $5900 \mathrm{ppm}$, which killed 99.15 and $99.84 \%$ of the virus in beef and lettuce, respectively (Fig. 4, B). Benzoic acid at concentrations of 100 to 5900 ppm killed 97.49 to $99.93 \%$ of FCV. The potent effect was observed with a concentration of $3000 \mathrm{ppm}$, which killed 99.92 and $99.93 \%$ of the virus in beef and lettuce, respectively (Fig. 4, C). Citric acid and lactic acid showed similar results compared to benzoic acid. At a concentration of $3000 \mathrm{ppm}$, citric acid killed 99.45 and $99.81 \%$ of the virus in beef and lettuce, respectively (Fig. 4, D). On beef and lettuce, lactic acid at a concentration of $3000 \mathrm{ppm}$ was found to be the most effective, killing $99.57 \%$ and $99.26 \%$ of the virus, respectively (Fig. 4, E). Propionic acid concentrations of $1000 \mathrm{ppm}$ appeared to be more effective than the other organic acids, with $99 \%$ virus inactivation occurring within 1 min (data not shown). Propionic acid was most effective at a concentration of $5900 \mathrm{ppm}$, killing $99.88 \%$ and $99.99 \%$ of the virus on beef and lettuce, respectively (Fig. 4, G). Overall, most organic acid treatments showed a disinfection efficacy $>99 \%$. These results are consistent with previous studies showing that FCV is quite unstable at lower $\mathrm{pH}$ values. However, it is important to note that most entero viruses are generally acid resistant, which is probably crucial for surviving the stomach environment and reaching the target cells in the small intestine (40). For example, the stability of FCV in a wide $\mathrm{pH}$ range, i.e., less than complete inactivation for $\mathrm{pH} 6$, was clearly higher than the $\mathrm{pH}$-dependent stability of $\mathrm{CaCV}$. With respect to the $\mathrm{pH}$ stability of the enteric noroviruses, it was shown that $3 \mathrm{hr}$ at $\mathrm{pH} 2.7$ (at room temperature) was not enough to completely inactivate $\mathrm{NV}$ in gastrointestinal conditions (i.e., low $\mathrm{pH}$ and high bile concentrations), other enteric viruses (e.g.,

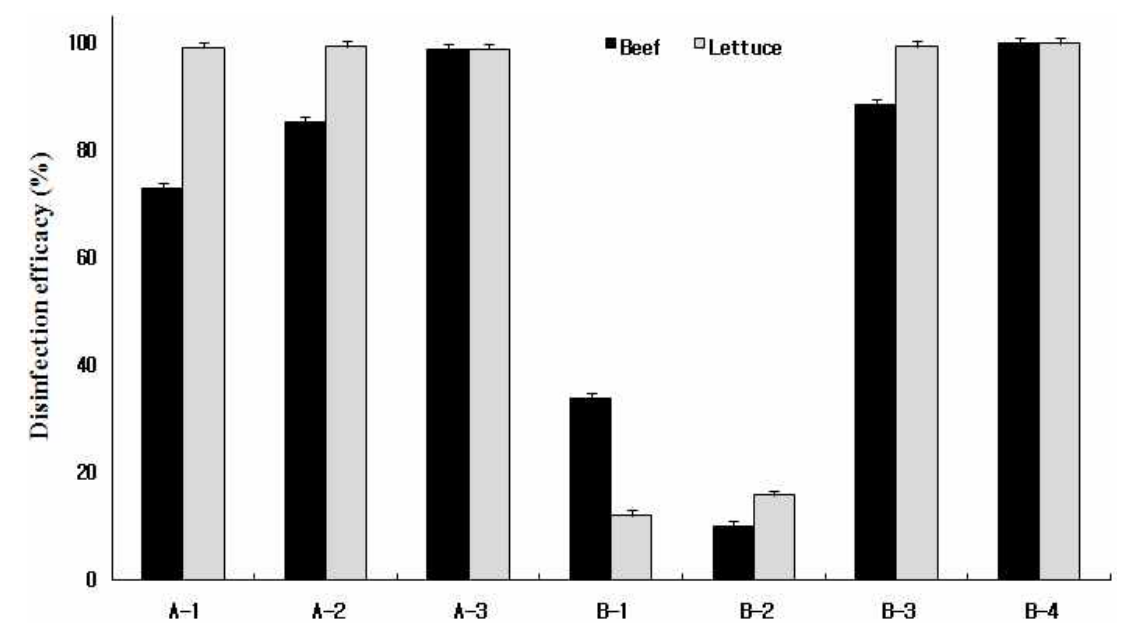

Fig 3. Comparison of the FCV inactivation efficacies of UV irradiation and drying after the inoculation of food surfaces (beef or lettuce). (A-1) UV $10 \mathrm{~min}$; (A-2) UV $20 \mathrm{~min}$; (A-3) UV $30 \mathrm{~min}$; (B-1) drying $10 \mathrm{~min}$; (B-2) drying $1 \mathrm{hr}$; (B-3) drying $12 \mathrm{hr}$; (B-4) drying $48 \mathrm{hr}$. 


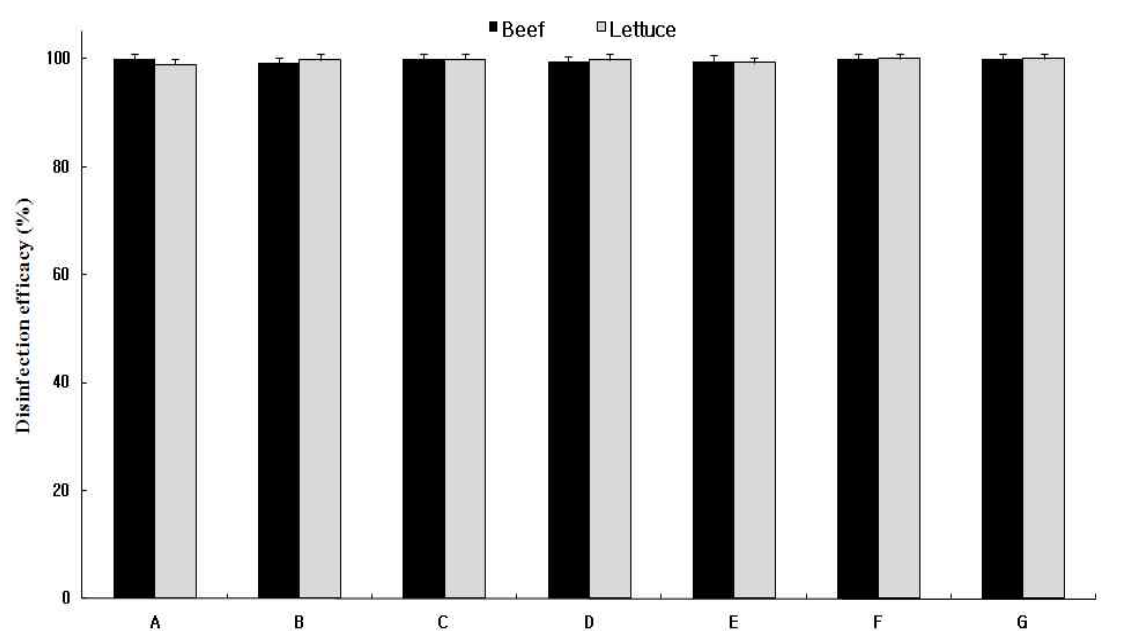

Fig 4. Comparison of the viral inactivation efficacies of organic acids in FCV-inoculated food surfaces (beef or lettuce). (A) acetic acid 3000 ppm; (B) acetic acid 5900 ppm; (C) benzoic acid 3000 ppm; (D) citric acid 3000 ppm; (E) lactic acid 3000 ppm; (F) propionic acid 3000 ppm; (G) propionic acid 5900 ppm.

poliovirus, hepatitis A virus, or rotavirus) might be better than the animal caliciviruses (13). Furthermore, organic solvent extraction is often an essential step in concentrating enteric viruses from environmental, food, and water samples $(6,22,35,36,38)$.

\section{Comprehensive analysis of the various treatments}

NVs are very stable in the environment (21). Therefore, in addition to direct person-to-person transmission, they may also be transmitted via contaminated environmental surfaces and hands. Thus, food handlers with contaminated hands represent a serious problem, as they may cause large-scale outbreaks. For this reason, the treatment of environmental surfaces and hands is very important to prevent NV transmission. The use of surrogate cultivable viruses has been recognized by the Environmental Protection Agency for the testing of antiviral disinfectants. The closely related FCV has been used previously as a model for NV inactivation studies (16). Considering the physicochemical and structural similarities between $\mathrm{NV}$ and FCV, it is reasonable to assume that an agent demonstrated to kill FCV will also kill NV when used under identical conditions. In a recent study, most commercial disinfectants proved to be ineffective against FCV at the manufacturer's recommended concentrations (12). In this study, the FCV-inactivating efficacy of various agents was quantified using inoculated ceramic, glass, and stainless steel surfaces. Regarding food contact surfaces, most agents proved to be more effective on ceramic or glass than on stainless steel. On ceramic and glass, FCV inactivation was highly effective with the use of chemical treatments and organic acids. However, iodine demonstrated a very low FCV inactivation efficacy on food contact surfaces. Regarding food surfaces, most agents proved to be more effective on lettuce than on beef. This suggests that the difference in surface texture of lettuce and beef may affect the virus survival. Organic acids may have been inactivated due to interactions with proteins on the beef surface. However, organic acid treatments were very effective overall on food surfaces. On food contact surfaces, ceramic surfaces were most easily disinfected, whereas stainless steel surfaces were more difficult to disinfect. Overall, the chemical treatments were more effective than the physical treatments for both food contact surfaces and food surfaces, perhaps because chemical treatments cause denaturation of viral capsid proteins.

In this study, we confirmed the effectiveness of commonly used sanitizers against the propagation of FCV, a virus very similar to that causing viral gastroenteritis in humans. Thus, these findings could be applied to prevent the cross-contamination of foodborne viruses and the subsequent spread of NV-associated foodborne illnesses.

\section{ACKNOWLEDGEMENT}

This work was supported by the research grant of the Chungbuk National University in 2009.

\section{REFERENCES}

1. Koopmans $\mathrm{M}$, von Bonsdorff $\mathrm{CH}$, Vinjé J, Medici D, Monroe S. 2002. Foodborne viruses. FEMS Microbiol Rev 26: $187-205$.

2. Richards GP, Cliver DO. 2001. Compendium of methods for the microbiological examination of foods. In Foodborne viruses. Downes FP, Ito K, eds. 4th ed. Ch. 44, American Public Health Association, Washington, DC, USA. $\mathrm{p}$ 447-461.

3. Cliver DO. 1995. Detection and control of foodborne viruses. Trends Food Sci Tech 6: 353-358.

4. Svensson L. 2000. Diagnosis of foodborne viral infections in patients. Int J Food Microbiol 59: 117-126.

5. Koopmans M, Durzer E. 2004. Foodborne viruses: An emerging problem. Int J Food Microbiol 90: 23-41.

6. Seymour IJ, Appleton H. 2001. Foodborne viruses and fresh produce. J Appl Microbiol 91: 759-773. 
7. Taku A, Gulati BR, Allwood PB, Palazzi K, Hedberg CW, Goyal SM. 2002. Concentration and detection of caliciviruses from food contact surfaces. J Food Prot 65: 9991004.

8. Widdowson MA, Sulka A, Bulens SN, Totaro J, Woron R, Mead PS, Bresee JS, Monroe SS, Glass RI. 2005. Norovirus and foodborne disease, United States, 19912000. Emerg Infect Dis 11: 95-102.

9. Korea Food and Drug Administration. Present condition of foodborne viruses. Available from: http://fm.kfda.go.kr. Accessed 4 August 2008.

10. Rabenau HF, Stürmer M, Buxbaum S, Walczok A, Preiser W, Doerr HW. 2003. Laboratory diagnosis of norovirus: Which method is the best? Intervirology 46: 232-238.

11. Biadawid S, Malika N, Adeqbunrinb O, Sattarb SA, Farber JM. 2003. A feline kidney cell line-based plaque assay for feline calicivirus, a surrogate for Norwalk virus. $J$ Virol Methods 107: 163-167.

12. Gulati BR, Allwood PB, Hedberg CW, Goyal SM. 2001. Efficacy of commonly used disinfectants for the inactivation of calicivirus on strawberry, lettuce, and a foodcontact surface. J Food Prot 64: 1430-1434.

13. Duizer E, Bijkerk P, Rockx B, Groot AD, Twisk F, Koopmans M. 2004. Inactivation of caliciviruses. Appl Environ Microbiol 41: 4538-4543.

14. LaBarre DD, Lowy RJ. 2001. Improvements in methods for calculating virus titer estimates from TCID $_{50}$ and plaque assays. J Virol Methods 96: 107-126.

15. D'Souza DH, Sair A, Williams K, Papafragkou E, Jean J, Moore C, Jaykus L. 2006. Persistence of caliciviruses on environmental surfaces and their transfer to food. Int $J$ Food Microbiol 108: 84-91.

16. Mattison K, Karthikeyan K, Abebe M, Malik N, Sattar SA, Farber JM, Bidawid S. 2007. Survival of calicivirus in foods and on surfaces: experiments with feline calicivirus as a surrogate for norovirus. J Food Prot 70: 500-503.

17. Doultree JC, Druce JD, Birch CJ, Bowden DS, Marshall JA. 1999. Inactivation of feline calicivirus, a Norwalk virus surrogate. $J$ Hosp Infect 41: 51-57.

18. Fleet GH, Heiskanen P, Reid I, Buckle KA. 2000. Foodborne viral illness-status in Australia. Int J Food Microbiol 59: 127-136.

19. Jimenez L, Chiang M. 2006. Virucidal activity of a quaternary ammonium compound disinfectant against feline calicivirus: A surrogate for norovirus. Am J Infect Control 34: 269-273.

16. Juven BJ, Pierson MD. 1996. Antibacterial effects of hydrogen peroxide and methods for its detection and sanitization. J Food Prot 59: 1233-1241.

20. Yashpal SM, Sunil M, Sagar MG. 2006. Comparative efficacy of ethanol and isopropanol against feline calicivirus, a norovirus surrogate. Am J Infect Control 34: 31-35.

21. Gehrke C, Steinmann J, Goroncy-Bermes P. 2004. Inactivation of feline calicivirus, a surrogate of norovirus (formerly Norwalk-like viruses), by different types of alcohol in vitro and in vivo. $J$ Hosp Infect 56: 49-55.

22. Tree JA, Adams MR, Lees DN. 2005. Disinfection of feline calicivirus (a surrogate for Norovirus) in wastewaters. J Appl Microbial 98: 155-162.

23. Cliver DO. 1997. Virus transmission via food. World Health Stat $Q$ 50: 90-101.

24. Wang QH, Costantini V, Saif LJ. 2007. Porcine enteric caliciviruses: genetic and antigenic relatedness to human caliciviruses, diagnosis and epidemiology. Vaccine 25: 5453-5466.
25. Allwood PB, Malik YS, Hedberg CW, Goyal SM. 2004. Effect of temperature and sanitizers on the survival of feline calicivirus, Escherichia coli, and F-specific coliphage MS2 on leafy salad vegetables. J Food Prot 67: 14511456.

26. Reed LJ, Muench H. 1983. A simple method of estimating fifty percent endpoint. Am J Hyg 27: 493-497.

27. Boxman IL, Dijkman R, te Loeke NA, Hägele G, Tilburg JJ, Vennema H, Koopmans M. 2009. Environmental swabs as a tool in norovirus outbreak investigation, including outbreaks on cruise ships. J Food Prot 72: 111-119.

28. Malik YS, Goyal SM. 2005. Virucidal efficacy of sodium bicarbonate on a food contact surface against feline calicivirus, a norovirus surrogate. Int J Food Microbiol 109: 160-163.

29. Bidawid S, Malik N, Adegbunrin O, Sattar SA, Farber JM. 2004. Norovirus cross-contamination during food handling and interruption of virus transfer by hand antisepsis: experiments with feline calicivirus as a surrogate. J Food Prot 67: 103-109.

30. Kusumaningrum HD, Riboldi G, Hazeleger WC, Beumer RR. 2003. Survival of foodborne pathogens on stainless steel surfaces and cross-contamination to foods. Int $J$ Food Microbiol 85: 227-236.

31. Rutala WA, Barbee SL, Aguiar NC, Sobsey MD, Weber DJ. 2000. Antimicrobial activity of home disinfectants and natural products against potential human pathogens. Infect Control Hosp Epidemiol 21: 33-38.

32. Valot S, Edert D, Faou LA. 2000. A simple method for the in vitro study of the virucidal activity of disinfectants. $J$ Virol Methods 86: 21-24.

33. Thurston-Enriquez JA, Haas CN, Jacangelo J, Riley K, Gerba CP. 2003. Inactivation of feline calicivirus and adenovirus type 40 by UV radiation. Appl Environ Microbiol 69: $577-582$.

34. Butot S, Putallaz T, Sánchez G. 2008. Effects of sanitation, freezing and frozen storage on enteric viruses in berries and herbs. Int J Food Microbiol 126: 30-35.

35. Karapinar M, Gönül SA. 1992. Effects of sodium bicarbonate, vinegar, acetic and citric acids on growth and survival of Yersinia enterocolitica. Int J Food Microbiol 16: 343-347.

36. Steinmann J. 2004. Surrogate viruses for testing virucidal efficacy of chemical disinfectants. J Hosp Infect 56: 549554.

37. Ukuku DO. 2004. Effect of hydrogen peroxide treatment on microbial quality and appearance of whole and freshcut melons contaminated with Salmonella spp. Int J Food Microbiol 95: 137-146.

38. Poschetto LF, Ike A, Papp T, Mohn U, Böhm R, Marschang RE. 2007. Comparison of the sensitivities of noroviruses and feline calicivirus to chemical disinfection under fieldlike conditions. Appl Environ Microbiol 73: 5494-5500.

39. Phillips CA, Duggan J. 2001. The effect of EDTA and trisodium phosphate, alone and in combination with nisin, on the growth of Arcobacter butzleri in culture. Food Microbiol 18: 547-554.

40. Cannon JL, Papafragkou E, Park GW, Osborne J, Jaykus LA, Vinjé J. 2006. Surrogates for the study of norovirus stability and inactivation in the environment: A comparison of murine norovirus and feline calicivirus. $J$ Food Prot 69: 2761-2765.

(Received January 8, 2010; Accepted June 20, 2010) 